\title{
The TGF- $\beta$ superfamily: new members, new receptors, and new genetic tests of function in different organisms
}

\author{
David M. Kingsley \\ Department of Developmental Biology, Beckman Center B300, Stanford University, Stanford, California 94305-5427 USA
}

In the last 10 years, a large family of secreted signaling molecules has been discovered that appear to mediate many key events in normal growth and development. The family is known as the TGF- $\beta$ superfamily (Massague 1990|, a name taken from the first member of the family to be isolated (transforming growth factor- $\beta 1$ ). This name is somewhat misleading, because TGF- $\beta 1$ has a large number of effects in different systems (Sporn and Roberts 1992). It actually inhibits the proliferation of many different cell lines, and its original "transforming" activity may be due to secondary effects on matrix production and synthesis of other growth factors (Moses et al. 1990). The two dozen other members of the TGF- $\beta$ superfamily have a remarkable range of activities. In Drosophila, a TGF- $\beta$-related gene is required for dorsoventral axis formation in early embryos, communication between tissue layers in gut development, and correct proximal distal patterning of adult appendages. In Xenopus, a TGF- $\beta$-related gene is expressed specifically at one end of fertilized eggs and may function in early signaling events that lay out the basic body plan. In mammals, TGF- $\beta$-related molecules have been found that control sexual development, pituitary hormone production, and the creation of bones and cartilage. The recognition of TGF- $\beta$ superfamily members in many different organisms and contexts provides one of the major unifying themes in recent molecular studies of animal growth and development.

The rough outlines of the TGF- $\beta$ family were first recognized in the 1980s. Since that time, a number of excellent reviews have appeared that summarize the properties of different family members (Ying 1989; Massague 1990; Lyons et al. 1991; Sporn and Roberts 1992). Here, I will focus on four areas that have seen major progress in the last 3 years: structural characterization of the signaling molecule, isolation of new family members, cloning of receptor molecules, and new genetic tests of the functions of these factors in different organisms.

\section{Structural studies}

The various members of the TGF- $\beta$ family are initially synthesized as larger precursor molecules with an amino-terminal signal sequence and a pro-domain of varying size (Fig. 1A). This precursor protein is usually cleaved at a dibasic or RXXR site to release a mature carboxy-terminal segment of 110-140 amino acids. The active signaling molecule is made up of hetero- or homodimers of this carboxy-terminal segment (Massague 1990).

The pro-domain of TGF- $\beta$ is poorly conserved across different family members, although often well conserved for a particular family member isolated from several different organisms. It appears to be required for normal synthesis and secretion of family members /Gray and Mason 1990; Hammonds et al. 1991; Thomsen and Melton 1993). It can also remain associated with the carboxy-terminal signaling fragment to produce an inactive complex (Gentry and Nash 1990). Activation of this complex by proteolyis or low $\mathrm{pH}$ may be an important physiological regulator of activity for the TGF- $\beta$ subclass of molecules. Similar latent complexes have not yet been found for other members of the TGF- $\beta$ superfamily.

The mature region is much more highly conserved and contains most of the sequence landmarks by which new family members are usually recognized. Seven cysteine residues within the mature region are nearly invariant in members of the family.

Recent crystallography studies of TGF- $\beta 2$ have shown that six of these cysteines are closely grouped to make a rigid structure called a cystine knot (Daopin et al. 1992; Schlunegger and Grutter 1992). The knot consists of an eight-member ring held together by two disulfide bonds, with a third disulfide bond threaded through the middle of the ring (see Fig. 1B). This knot locks the base of several $\beta$-sheet strands together and probably accounts for the strong resistance of many TGF- $\beta$ family members to heat, denaturants, and extremes of $\mathrm{pH}$. The remaining cysteine residue in each monomer forms an additional disulfide bond that links two monomers into a dimer. This cysteine is missing in two newly discovered members of the family GDF-3 and GDF-9 (see below). Many hydrophobic contacts exist between the two monomer subunits that may promote dimer formation even in the absence of this disulfide bond. The overall structure of the dimer is surprisingly open and contains several water molecules in its center. 

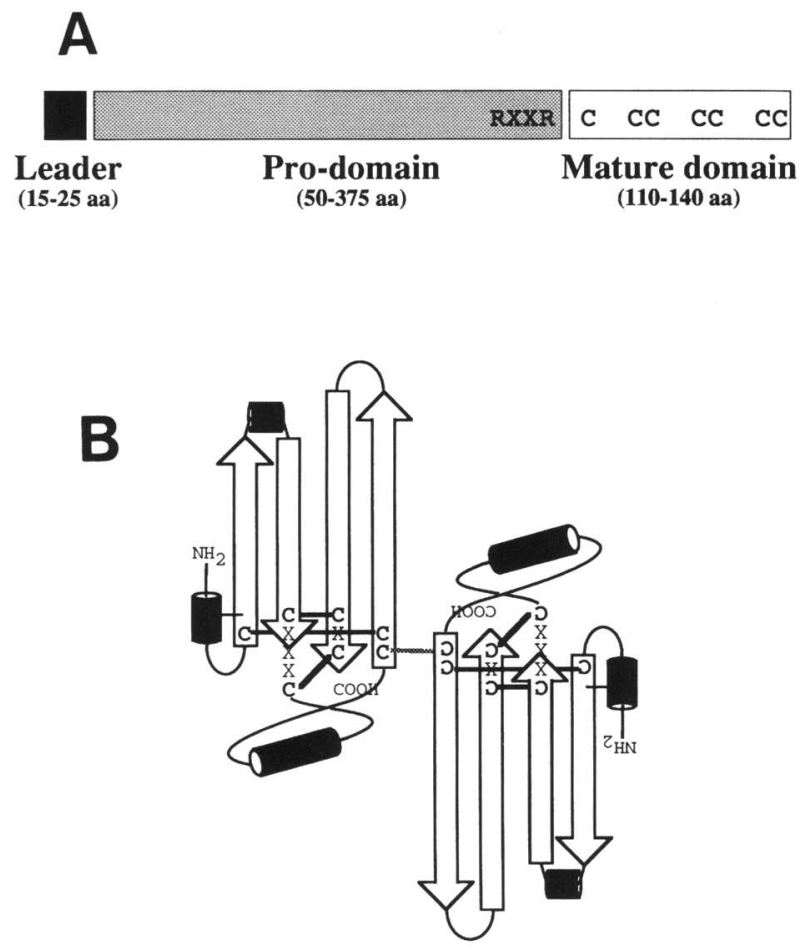

Figure 1. Structure of TGF- $\beta$ superfamily members. $(A)$ TGF$\beta$-related proteins are synthesized as larger precursor proteins. An amino-terminal signal targets the precursor to the secretory pathway. A variable pro-domain may assist in folding, dimerization, and regulation of factor activity. The actual signaling molecule is a homo- or heterodimer of a small carboxy-terminal fragment. Seven characteristic cysteine residues in this region are nearly invariant in various members of the superfamily. $(B)$ Crystal structure of the mature region of TGF- $\beta 2$. Six of the characteristic cysteine residues form three disulfide bonds within each monomer subunit. The seventh cysteine forms a disulfide bond linking two monomers into a dimer. Much of the variation between members of the family are in the aminoterminal $\alpha$-helix and the loops and helices that join the various $\beta$-sheet strands (Daopin et al. 1992; Schlunegger and Grutter 19921.

The differences between TGF- $\beta$ family members map to several different regions of the molecule (Schlunegger and Grutter 1992). The amino-terminal region varies greatly in both length and sequence. This region forms an $\alpha$-helix in TGF- $\beta 2$, which is linked to the remainder of the monomer by an additional disulfide bridge. This bridge is missing in most other members of the family, and the structure of the corresponding amino-terminal extension is not known. This amino terminus can be truncated without affecting the known biological activities of one family member, dorsalin (Basler et al. 1993). TGF- $\beta 1$ is 100 -fold more potent than TGF- $\beta 2$ at inhibiting the proliferation of endothelial cells. Domain swap experiments suggest that the different potencies map to a 42-amino-acid region that includes the longest $\alpha$-helix in the monomer (Qian et al. 1992). Additional mutagenesis, binding, and structural studies are required to iden- tify the portions of the molecule responsible for interacting with receptors.

Crystallography studies have revealed unsuspected similarity between members of the TGF- $\beta$ superfamily and members of the nerve growth factor (NGF) and platelet-derived growth factor (PDGF) families (McDonald and Hendrickson 1993). NGF and PDGF monomers show $<10 \%$ amino acid sequence similarity with TGF$\beta$. All of these factors contain the cysteine knot motif, however, and the three-dimensional structures of the cores of the monomers are nearly superimposable. These similarities suggest that all three growth factor families are derived from a common ancestor. This ancestor may have been particularly resistant to denaturation and extremes of $\mathrm{pH}$, providing a convenient basis for later diversification of other signaling molecules that could survive in various extracellular enviornments.

Interestingly, the interactions between the monomer subunits are completely different in the active signaling dimers of TGF- $\beta$, NGF, and PDGF, involving different faces of the subunits, different orientations, and different axes of symmetry (McDonald and Hendrickson 1993). These differences suggest that the receptor interactions (and presumably the functions) of the TGF- $\beta$, NGF, and PDGF families have evolved separately. It is thus still useful to consider the groups separately, despite their common membership in the cystine-knot super-super family.

\section{New members and families within families}

The TGF- $\beta$ superfamily has grown from $\sim 17$ molecules in 1990 to at least 25 members at the time of this writing. A rough overview of the members of the family is shown in Figure 1 and described below /with members reported since 1990 listed in bold). Note that some of the molecules can be grouped into distinct subfamilies with highly related sequences (Table 1). The most obvious subfamilies include the following.

\section{The TGF- $\beta$ subfamily}

At least four genes have been found that are much more similar to TGF- $\beta 1$ than to other members of the TGF- $\beta$ superfamily. These molecules were originally named TGF- $\beta 2,-\beta 3,-\beta 4$, and $-\beta 5$, but are derived from several different species. Evolutionary considerations suggest that TGF- $\beta 4$ is probably the chick homolog of mammalian TGF- $\beta 1$ (Burt and Paton 1992). Most of the TGF- $\beta$ molecules have qualitatively similar activities in different systems (Massague 1990).

\section{Activin subfamily}

Activins are homo- or heterodimers of two subunits, $A$ or B [also called inhibin $\beta$ A (InhbA) and inhibin $\beta$ B (InhbB)]. These subunits are related much more closely to each other than to other members of the TGF- $\beta$ superfamily. The A and B subunits can form dimers with another subunit called inhibin $\alpha(\operatorname{Inh} \alpha)$. This subunit is 
Table 1. Sequence relationships between members of the TGF- $\beta$ superfamily

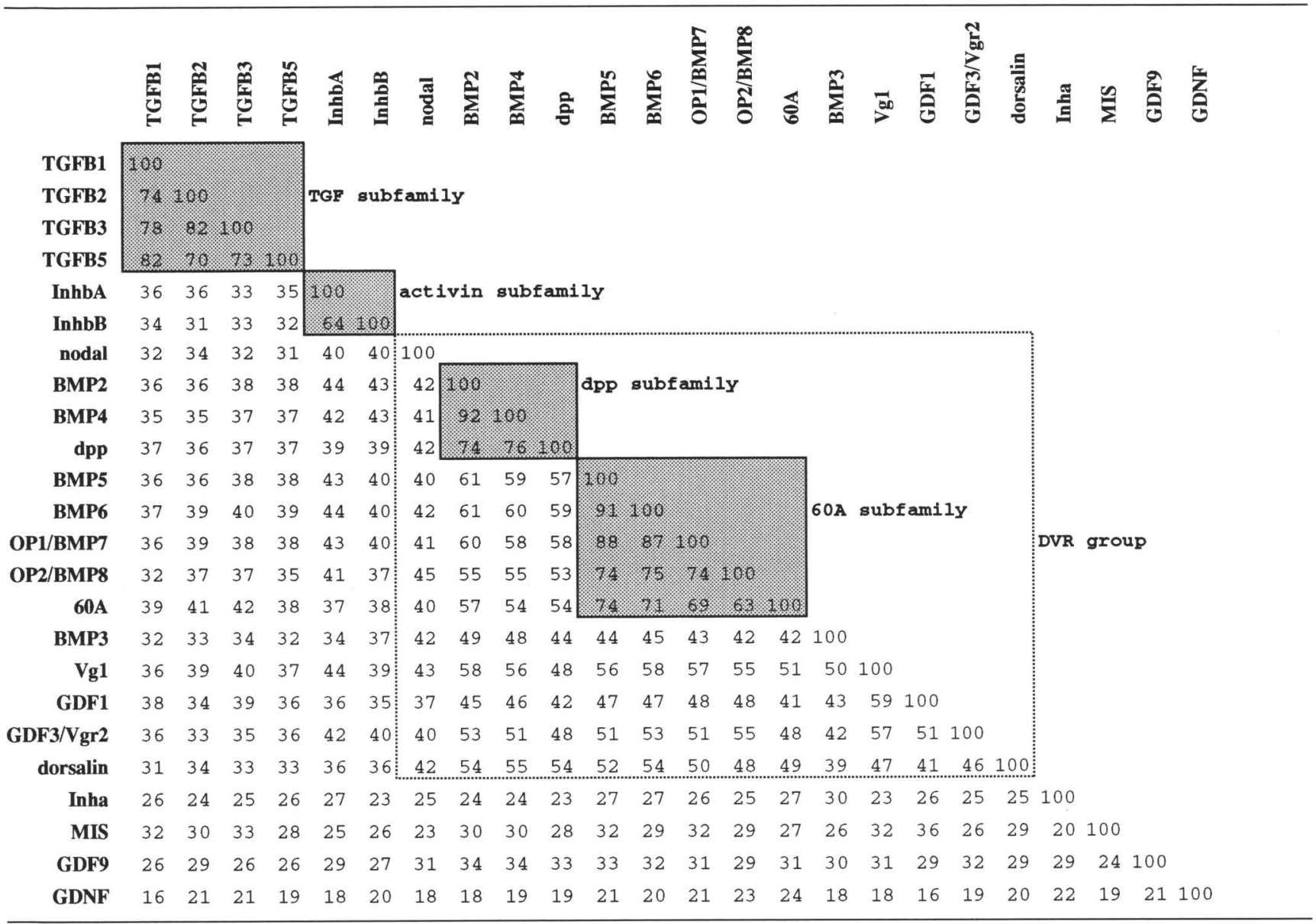

The different TGF- $\beta$ family members were aligned beginning with the first invariant cysteine residue in the mature region of the molecules. Percent amino acid identities are shown for all pairwise combinations. Phylogenetic analysis using Clustal V (Higgins et al. 1992) confirms that several of the molecules fall into distinct evolutionary subgroups (shaded). These groups are strongly supported by bootstrap analysis of phylogenetic trees (Felsenstein 1985). A looser grouping of DVR molecules has also been suggested on the basis of overall similarity relationships (Lyons et al. 1991). Human sequences were chosen for analysis, with the following exceptions: $d p p$ and 60A (Drosophila); TGF- $\beta 5$ and Vg1 (Xenopus); dorsalin (chick); GDF3/Vgr2 and nodal (mouse).

much more distantly related and does not belong to any particular subgroup. The inhibins and activins have opposite biological effects on many systems-a particularly clear example of how dimerizing with different partners can drastically alter the activities of TGF- $\beta$ family members (Ying 1989).

\section{The decapentaplegic subfamily}

The Drosophila decapentaplegic (dpp) gene plays an essential role during several distinct stages of Drosophila development (see below). Two mammalian homologs of the $d p p$ gene were found during the purification of factors that can induce the formation of ectopic bone and cartilage when implanted under the skin or into muscles (Wozney et al. 1988). The mammalian factors [bone morphogenetic proteins 2 and 4 (BMP2 and BMP4)] are $\sim 90 \%$ identical to each other in the mature signaling portion of the molecule and $75 \%$ identical to DPP (Table 1). The similarity between the fly and mammalian genes extends to the functional level. Human BMP4 sequences can rescue the dorsoventral axis defects caused by $d p p$ mutations in Drosophila (Padgett et al. 1993). Conversely, purified preparations of the DPP protein can induce bone and cartilage in mammals (Sampath et al. 1993|.

\section{The 60A subfamily}

This group also contains a single Drosophila gene and a number of mammalian homologs with osteoinductive activity. The Drosophila gene was isolated in a specific search for TGF- $\beta$ homologs in flies (Wharton et al. 1991, Doctor et al. 1992). It has been named $\mathbf{6 0 A}$ after its chromosomal map location, but its normal function is not yet known. Four mammalian members of this subgroup were either discovered in highly purified preparations of bone-inducing material or were isolated by homology to 
other members of the family: (1) BMP5 (Celeste et al. 1990); (2) Vgr-1 or BMP6 (Lyons et al. 1989a; Celeste et al. 1990); (3) BMP7 or osteogenic protein 1(OP-1) (Celeste et al. 1990; Ozkaynak et al. 1990); and (4) osteogenic protein 2 (OP-2) or BMP8 (Ozkaynak et al. 1992).

\section{The DVR group}

The DPP and 60A subfamilies are related more closely to one another than to TGF- $\beta$ s or activins and have often been grouped together as part of a larger collection of molecules called DVR (ㅁpp and Vg1 related) (Lyons et al. 1991). The DVR grouping is supported by percent similarity scores (Table 1) and by evolutionary analysis based on parsimony. The borders of the group are blurry, however, and are not strongly supported by bootstrap analysis of phylogenetic trees (Felsenstein 1985). Other molecules traditionally assigned to the DVR group include the prototypical Vg1 gene, originally isolated because of its asymmetric distribution in Xenopus oocytes (Weeks and Melton 1987), and the BMP3 or osteogenin gene (Wozney et al. 1988; Luyten et al. 1989), another osteoinductive factor in mammals. New DVR-like genes include the following.

Growth differentiation factor 1 GDF-1 was isolated during a screen for additional mammalian members of the TGF- $\beta$ superfamily. It is expressed primarily in the nervous system and is encoded by an unusual bicistronic message (Lee 1991). A large separate open reading frame in the GDF-1 transcript encodes a protein predicted to have multiple transmembrane-spanning regions. This second open reading frame is highly conserved between mice and humans, and clear homologs have recently been reported in both yeast and Caenorhabditis elegans (Waterston et al. 1992; Boyer et al. 1993). In prokaryotes, genes that are encoded by polycistronic messages are usually functionally related. It will be interesting to see whether this is also true of the two potential molecules encoded by GDF-1 transcripts.

GDF-3/Vgr-2 This member of the DVR group was also isolated by homology to other family members. It has been called Vg-related gene 2 (Vgr2) or growth differentiation factor 3 (GDF-3) by the two groups that independently isolated it (Jones et al. 1992b; McPherron and Lee 1993). Although it cannot be clearly assigned to any of the previously known sequence subgroups within the DVR family, its highest similarities scores are with Vg-1, BMP2, BMP6, and GDF-1. The GDF-3/Vgr-2 protein product is one of the only molecules in the TGF- $\beta$ superfamily that lacks one of the seven cysteine residues normally found in the mature region. The missing cysteine residue normally forms the interchain disulfide bond that links two monomer subunits into a dimer (Fig. 1). It is not clear whether this linkage is essential for normal dimer formation. The GDF-3/Vgr-2 gene is expressed in ossifying skeletal tissue during embryonic development (Jones et al. 1992b) and in thymus, spleen, bone marrow, and adipose tissue in adults (McPherron and Lee 1993).

dorsalin A screen for TGF- $\beta$ family members expressed in the developing chick nervous system identified a molecule expressed preferentially in the dorsal side of the developing neural tube (dorsalin, Fig. 3, below) (Basler et al. 1993). This molecule has two in vitro activities that suggest it may play an important role in neural patterning along the dorsovental axis. It promotes the outgrowth of neural crest cells (which normally emigrate from the dorsal side of the neural tube), and it inhibits the formation of motor neuron cells, (which are normally found only on the ventral side of the spinal cord). Its possible roles outside the nervous system have not yet been described, but like BMP molecules, dorsalin will stimulate the production of alkaline phosphatase by bone marrow cell lines.

nodal The nodal gene was identified at the site of a retroviral insertion that causes an early embryonic lethal phenotype in mice (Zhou et al. 1993). The predicted product of the gene is about equally similar to the DVR and activin subfamilies and provides a good example of the difficulty in defining the borders of the DVR class. The properties of the gene are described in more detail below in the section describing genetic studies of TGF- $\beta$ family members.

\section{Divergent genes}

Müllerian inhibiting substance (MIS) and the Inh $\alpha$ subunit are distantly related to the other members in the TGF- $\beta$ superfamily (Massague 1990). Two additional divergent family members have recently been found. The GDF-9 gene was isolated in a PCR screen for additional family members (McPherron and Lee 1993). Like the $G D F-3 / V g r 2$ gene, its predicted protein product lacks the cysteine residue predicted to covalently link monomers into a dimer. Transcripts of the gene are expressed only in ovaries of adult animals.

Glial-derived neurotropic growth factor (GDNF) This factor was isolated based on its ability to promote the survival and differentiation of dopaminergic neurons from the midbrain (Lin et al. 1993). The factor shares the pattern of seven regularly spaced cyteines found in other members of the TGF- $\beta$ superfamily, but otherwise shares $<25 \%$ amino acid identity with other members of the family. Midbrain dopaminergic neurons are the major class of neurons lost in Parkinson's disease. The clinical importance of dopaminergic neurons will likely stimulate a great deal of future research on the in vitro and in vivo effects of this factor.

\section{Receptor molecules}

Major progress has been made in the last 3 years in isolating signaling receptors for various members of the TGF- $\beta$ superfamily. Recently isolated receptors for TGF- 
$\beta$, activins, and BMPs all belong to a novel new family of transmembrane receptors that contain a serine/threonine kinase domain on their cytoplasmic surface (Massague 1992; Lin and Lodish 1993). Ligand binding is presumed to stimulate the serine/threonine kinase activity of these receptors, perhaps by inducing the formation of receptor dimers or multimers. Although the substrates for the receptors are still largely unknown, the recognition of this new receptor family provides a clear starting point for future studies of the detailed molecular mechanisms of action of TGF- $\beta$ superfamily members on cells.

\section{Type II receptors}

The nomenclature for TGF- $\beta$ superfamily receptors grows out of pioneering biochemical studies of TGF- $\beta 1$ binding proteins. Early studies showed that TGF- $\beta 1$ binds to at least three major cell-surface proteins found on many cell types, termed type I, type II, and type III receptors based on their approximate sizes of 53, 70-85, and 200-400 kD (Massague 1990). The type I and type II receptors were the best candidates for signaling receptors, because they are the only receptors lost in mutant cell lines selected for resistance to the growth inhibitory effects of TGF- $\beta 1$ and TGF- $\beta 2$ (Laiho et al. 1990).

Expression cloning of the activin type II receptor provided the first indication that members of the TGF- $\beta$ superfamily signaled through transmembrane serine/ threonine kinases (Mathews and Vale 1991). The mouse activin receptor is a 503-amino-acid protein with an amino-terminal signal sequence, a small extracellular domain of 115 residues, a single hydrophobic transmembrane-spanning region, and an intracellular region containing a serine/threonine kinase domain (Fig. 2). Subsequent work identified a second activin receptor type II gene $(A c t R I I B)$ that can be alternatively spliced to produce at least four additional receptor isoforms varying three- to fourfold in their affinity for activin (Attisano et al. 1992; Mathews et al. 1992). The different isoforms may contribute to the striking concentration dependence of activin's effects on cells (Green et al. 1992).

The first type II receptor for the TGF- $\beta$ subclass of molecules was also isolated by expression cloning (Lin et al. 1992). The TGF- $\beta$ receptor shows very limited homology to the activin receptor in the extracellular domain $<10 \%$ identity) but extensive homology in the intracellular kinase domain (see Table 2). The purified intracellular domain will phosphorylate itself in vitro on serine and threonine residues (Lin et al. 1992). In addition, mutations that disrupt the kinase domain block signaling by the receptor (Wrana et al. 1992).

The C. elegans daf- 4 gene encodes a new type II transmembrane receptor (Estevez et al. 1993). Although the worm ligand for the daf-4 receptor has not yet been identified, the receptor will bind mammalian BMP2 and BMP4 with a $K_{\mathrm{d}}$ of $\sim 4 \mathrm{nM}$. This binding is not inhibited by TGF- $\beta$ or activin. Binding to the $60 \mathrm{~A}$ subclass of BMPs has not yet been tested. Mutations that disrupt

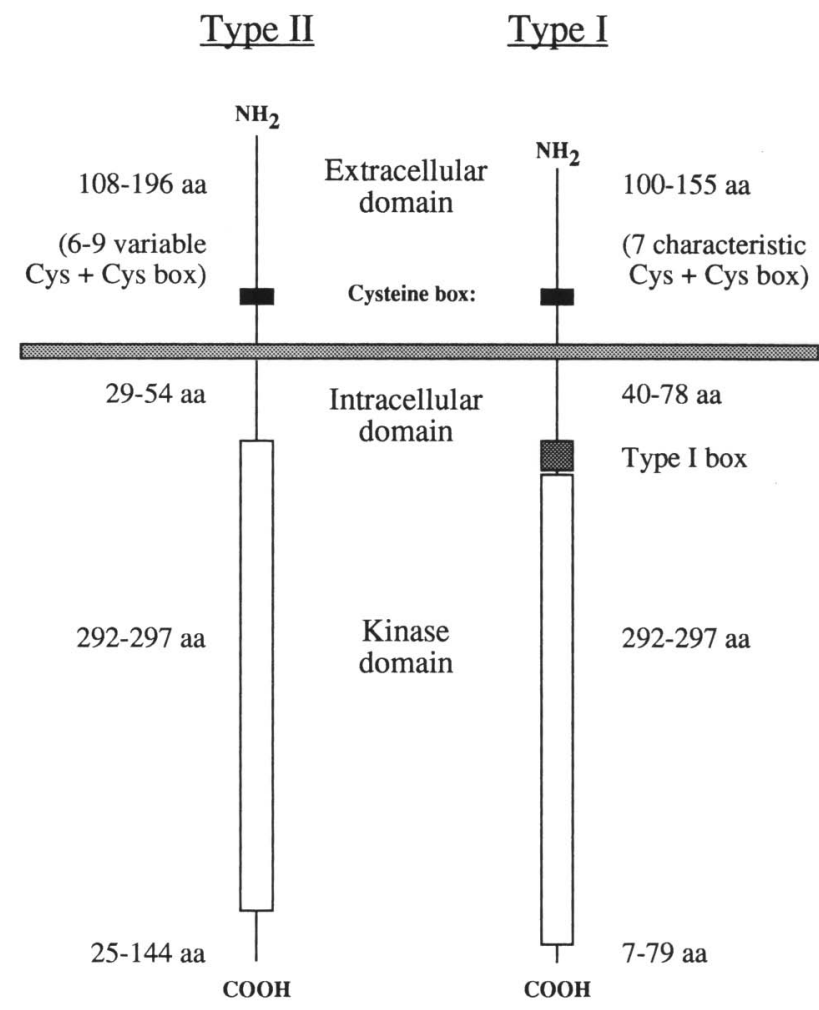

Figure 2. Signaling receptors for TGF- $\beta$ superfamily members. Both type I and type II receptors are transmembrane proteins with an amino-terminal signal peptide, a small extracellular region, a single hydrophobic transmembrane helix, and a cytoplasmic domain predicted to have serine/threonine kinase activity. A 9-amino-acid cysteine box $\left(\mathrm{CCX}_{4-5} \mathrm{CN}\right)$ is found in the extracellular domain of both receptor types. Type I receptors differ from type II receptors in the sequence of the kinase domain, the presence of a short series of tandem Ser/Gly residues and other conserved amino acids immediately preceding the kinase domain (here called the Type I box), and a characteristic pattern of seven extracellular cysteine residues preceding the cysteine box in the extracellular domain $\left(\mathrm{CXCX}_{3-5} \mathrm{C}_{4-25} \mathrm{C}_{4-5} \mathrm{C}_{13}\right.$. $\left.{ }_{16} \mathrm{GC} . \mathrm{X}_{7-19} \mathrm{CX}_{11-13}\right)$. A variety of experiments suggest that both types of receptors are required for normal signaling and probably form a heteromeric complex (see text).

daf- 4 gene function map in the kinase domain of the receptor, again confirming the importance of this region.

\section{Dual requirement for type II and type I receptors}

Although type II receptors have both an extracellular binding domain and an intracellular signaling domain, they may not be sufficient for normal signaling. Several somatic cell mutants resistant to the growth inhibitory effects of TGF have been isolated previously (Laiho et al. 1990; Inagaki et al. 1993). Some of the mutants lose just type I receptors, some lose both type I and type II receptors, and some maintain both receptors but are unable to signal. The mutants that have lost only type I receptors cannot be corrected with the cloned type II receptor (Wrana et al. 1992). In these cells, TGF- $\beta$ can bind the 
type II receptor on the cell surface, but binding does not lead to transcriptional and growth inhibitory responses.

Mutants that have lost both type I and type II receptors can be rescued by reintroducing the cloned type II receptor. Both type I and type II receptors reappear in transfected cells (Wrana et al. 1992; Inagaki et al. 1993). Sequencing studies have confirmed that some of these double receptor negative mutants have point mutations in the type II receptor gene (Wrana et al. 1992). These studies suggest that the type II receptor is essential for appearance of functional type I receptors on the cell surface. The type II receptor could be required for normal synthesis, processing, or transport of the type I receptor, or for binding of TGF- $\beta$ to the type I protein.

\section{Type I receptors}

The dual requirement for type I and type II receptors has led to great interest in the nature of the type I receptor molecule. Recent studies by several laboratories suggest that type I receptors are also transmembrane serine/threonine kinases (Attisano et al. 1993; Ebner et al. 1993b; Franzén et al. 1993). The type I receptors form a distinct subgroup in the receptor family based on the sequence of the kinase domain, amino acid similarities immediately preceding the kinase domain, and similar patterns of extracellular cysteine residues (Fig. 2; Table 2). Similar sequence features are seen in several other recently isolated transmembrane serine/threonine kinases, suggesting that they represent type I receptors for ligands not yet identified (see footnote to Table 2).

Several experiments suggest that the type I and type II receptors interact physically and functionally. The type I receptors only show binding activity when coexpressed with type II receptors (Attisano et al. 1993; Ebner et al. 1993b). This property explains why these receptors have been difficult to isolate using expression cloning approaches, and why initial studies of their ligand specificity (Matsuzaki et al. 1993) have been revised by subsequent studies (Attisano et al. 1993; Ebner et al. 1993a,b). Surprisingly, the binding specificity of type I receptors may depend on the particular type II receptor with which they are coexpressed. The same type I subunit will bind either activin or TGF- $\beta$, depending on whether it is coexpressed with the activin or TGF- $\beta$ type II receptor (Attisano et al. 1993; Ebner et al. 1993a). Conversely, the

Table 2. Sequence relationships between transmembrane serine/threonine kinase receptors

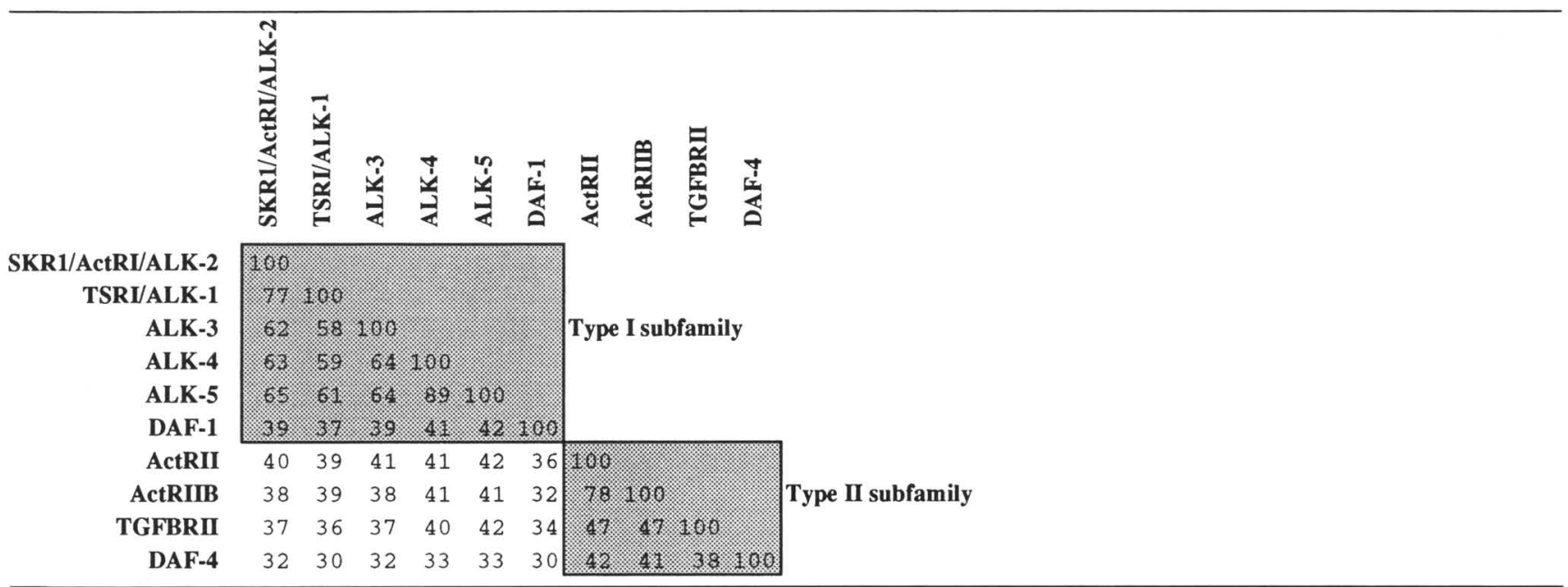

The different receptor molecules were aligned across the intracellular kinase domain. Percent amino acid identities are shown for all pairwise combinations. Phylogenetic analysis using Clustal V (Higgins et al. 1992) suggests that they fall into two distinct subgroups, type I and type II (shaded). Although the daf-1 receptor shows limited sequence homology to both type I and type II receptors and has previously been grouped more closely with type II receptors (ten Dijke et al. 1993), bootstrap analysis (Felsenstein 1985) strongly supports the grouping with type I receptors shown here. In addition, the spacing of cysteine residues in the extracellular domain of the daf-1 receptor closely resembles the characteristic pattern seen in type I receptors, and the daf-1 receptor contains some of the characteristic amino acids in the type I box upstream of the kinase domain, including a short Ser/Gly repeat. The sequences shown come from several different organisms and have been given different names by different groups. Where possible, human sequences have been used, including sequences for TGF- $\beta$ superfamily receptor-1 (Attisano et al. 1993) or activin receptor-like kinase 1 (ten Dijke et al. 1993), (TSR-I/ALK-1); serine threonine kinase receptor 1 (Matsuzaki et al. 1993), activin receptor I (Attisano et al. 1993), or activin receptor-like kinase 2 (ten Dijke et al. 1993), (SKR-1/ActRI/ALK-2); activin receptor-like kinases 3, 4, and 5 (ten Dijke et al. 1993), (ALK-3,4, and 5); and TGF- $\beta$ type II receptor (Lin et al. 1992), (TGFBRII). The activin type II and IIB receptor (ActRII and ActRIIB) sequences are from mouse (Mathews and Vale 1991; Attisano et al. 1992), and the DAF-1 and DAF-4 sequences are from worms (Georgi et al. 1990; Estevez et al. 1993). Note that several other receptors have been isolated from other organisms. The mouse Tsk-7L (Ebner et al. 1993b) and rat Rl (He et al. 1993) receptors group with the human SKRl/ActR1/ALK-2 receptor in phylogenetic analysis with Clustal V. The rat R2, R3, and R4 receptors (He et al. 1993) group with the human ALK-4, TSR-1/ALK-1, and ALK-5 receptors, respectively. The chick receptor protein kinase-1 (RPK-1) (Yamazaki et al. 1993) groups with the human ALK-3 receptor. 
signaling properties of the type II receptors change, depending on the specific type I receptor with which they are coexpressed. Activin will stimulate particular transcriptional responses in cells expressing the activin type II receptor and one of the activin type I receptors but not in cells expressing the same type II and a different type I receptor (Attisano et al. 1993).

Antibodies to either type I or type II receptors will coimmunoprecipitate both type I and type II subunits after cross-linking in the presence of ligand (Wrana et al. 1992; Attisano et al. 1993; Ebner et al. 1993a; Franzén et al. 1993). Type I and type II receptors thus appear to form complexes, although it is not yet clear whether the complexes exist in the absence of ligands or are driven by the dimeric nature of the ligands themselves.

The studies to date clearly suggest that combinatorial interactions between receptor subunits will be a major mechanism for controlling different cellular responses to TGF- $\beta$-like molecules. Members of the TGF- $\beta$ superfamily are already known to form either homo- or heterodimers. Particular combinations of ligand subunits may drive the formation of distinct receptor complexes, thus coupling different ligands to different cellular responses. Conversely, different cells may express different types of receptors for the same ligand. With a large number of receptor subunits and receptor isoforms, it is easy to imagine how the same factor may evoke different responses in different tissues or at different times, one of the major themes of recent studies of the role of these factors in normal development (see below).

\section{Other binding proteins}

A number of other soluble and cell-surface proteins have also been described that bind various TGF- $\beta$ superfamily members (Massague 1990; Lin and Lodish 1993). These proteins may mask or enhance effects of family members, target them to particular tissues or extracellular matrix sites, or affect their clearance from the circulation, from tissues, or from the cell surface. Three wellstudied examples include ( 1 ) a binding protein that is found in a latent complex with the TGF- $\beta 1$ pro- and mature domain (Kanzaki et al. 1990; Tsuji et al. 1990; Miyazono et al. 1991), (2) a soluble glycoprotein made by ovaries that binds activin and blocks the effects of activin on pituitary cells (follistatin) (Ying 1989), and (3) a cell-surface proteoglycan called betaglycan or the type III receptor that may present different TGF- $\beta$ isoforms to the type II signaling receptor (Wang et al. 1991; Lopez et al. 1993). In the absence of betaglycan, a small number of type II receptors show high affinity binding to TGF- $\beta 1$ or TGF- $\beta 3$ and fivefold lower affinity for TGF- $\beta 2$. In the presence of betaglycan, a large number of type II receptors are able to bind all three TGF- $\beta$ isoforms with high affinity. It is not yet clear whether other TGF- $\beta$-binding proteins have similar effects. Some of these molecules may represent other signaling receptors in their own right or may signal through mechanisms that have not yet been identified.

\section{Genetic tests of function}

For many years the primary information available for most members of the TGF- $\beta$ superfamily has been their sequence, their normal expression patterns, and their biological effects when added to cultured cells or animals. Although this has led to many hypotheses about their normal function, most of these roles still need to be confirmed by examining the phenotypic effects of inactivating the factor during normal development. This has now been possible in several cases.

\section{Flies and dpp}

The $d p p$ locus in Drosophila is the best-studied member of the superfamily in genetic terms. The name decapentaplegic refers to the 15 or more defects that are caused by mutations in the gene (Spencer et al. 1982). Only some of these will be mentioned here.

Dorsoventral axis During early development, the $d p p$ gene product appears to act as a secreted morphogen that helps to set up the dorsoventral axis of the embryo (Ferguson and Anderson 1992a; Wharton et al. 1993). Loss-of-function mutations in the dpp gene cause an expansion of ventral structures into the dorsal-most $40 \%$ of the embryo. These mutations are lethal even when heterozygous, suggesting that the level of the $d p p$ gene product is crucial for normal development. Extra copies of the $d p p$ gene cause the opposite effect, the expansion of dorsal structures (Wharton et al. 1993). In addition, injections of transcripts from the dpp gene lead to formation of a new dorsoventral axis in mutant embryos that lack maternal and zygotic determinants of dorsoventral polarity (Ferguson and Anderson 1992a). The site of injection determines the orientation of this axis, and the amount injected determines the type and extent of dorsal structures. The $d p p$ gene product is the best existing candidate for a long sought class of molecule in development, a secreted signaling molecule that can specify different cell fates at different concentrations (Slack 1993).

Transcripts from the $d p p$ gene are localized specifically in the dorsal $40 \%$ of the embryo (see Fig. 3), the same region affected by $d p p$ mutations (St. Johnston and Gelbart 1987). An activity gradient of $d p p$ is presumed to exist within this region but has not yet been demonstrated directly. Several genes have been identified that may modulate the activity of $d p p$ along the dorsoventral axis (Ferguson and Anderson 1992b). One of these genes (tolloid) encodes a secreted protein with homology to metalloproteases (Shimell et al. 1991). In mammals, a similar protein called BMP1 copurifies with other bone morphogenetic proteins, including the presumed mammalian homologs of $d p p$ (Wozney et al. 1988). In sea urchins, related proteins are expressed along the embryonic axis in a manner strikingly reminiscent of the localized expression of $d p p$ and tolloid in Drosophila (Fig. 3) (Lepage et al. 1992; Reynolds et al. 1992). BMP1/tolloid-like proteins are clearly ancient and must play an 
Figure 3. Axis formation in diverse organisms may involve TGF- $\beta$ family members or associated proteins. The $d p p$ gene is normally expressed in the dorsal $40 \%$ of the Drosophila embryo and appears to act as a morphogen that specifies increasingly dorsal fates at increasingly higher levels of activity (Ferguson and Anderson 1992a; Wharton et al. 1993). The BP10 and SpAN proteins of sea urchins are homologous to tolloid and BMP1 protease-like molecules that interact functionally and physically with members of the DPP/BMP group of

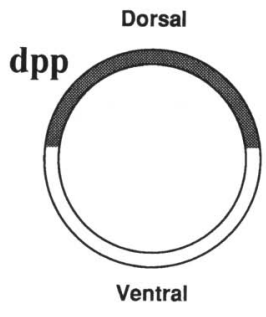

$$
\begin{gathered}
\text { Drosophila } \\
\text { embryo }
\end{gathered}
$$

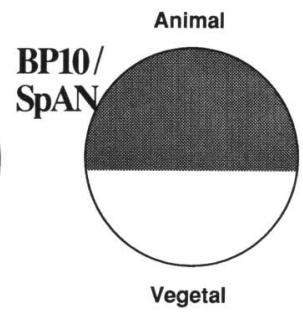

Sea urchin
blastula

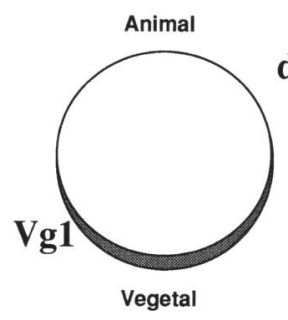

Xenopus oocytes

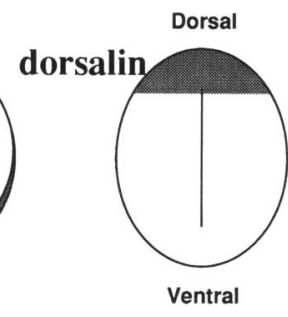

Chick spinal cord

molecules (Lepage et al. 1992; Reynolds et al. 1992). Antibodies to BP10 interfere with normal development of the animal half of the embryo (Lepage et al. 1992). Transcripts from the Vg1 gene accumulate at the vegetal pole of Xenopus oocytes (Weeks and Melton 1987). Regional activation of the Vgl protein may produce an early signal that induces mesoderm from the overlying animal region (Thomsen and Melton 1993). The dorsalin gene is expressed in the dorsal region of the chick spinal cord and may normally promote the emigration of neural crest and inhibit the formation of motor neurons in the dorsal region (Basler et al. 1993).

important, though not yet understood, role in the DPP/ BMP signaling pathway. Several other Drosophila genes may help in identifying additional molecules that affect the production, distribution, or reception of DPP/BMP signals (Ferguson and Anderson 1992b).

Gut development The dpp gene is also required for normal gut development in Drosophila (Immerglück et al. 1990; Panganiban et al. 1990; Reuter et al. 1990). It is expressed in visceral mesoderm cells along particular regions of the developing intestine, a pattern that is dependent on expression of the Ultrabithorax (Ubx) homeotic gene in the same regions. The protein product of the $d p p$ gene then spreads to the overlying intestinal epithelial cells. This expression is required for normal induction of the labial homeotic genes in the epithelial cells. In the absence of the $d p p$ gene product, labial is not expressed and a characteristic constriction fails to form in the midgut. This is a particularly well-worked out example of mesenchymal epithelial interactions in normal organ development. Secretion of the $D P P$ protein arries a signal from the segmented visceral mesoderm to the unsegmented gut epithelium, ultimately resulting in the formation of new morphological divisions in the intestine.

Imaginal discs Mutations at the $d p p$ locus were first recognized by their profound effects on the size and patterning of many adult appendages such as wings, eyes, antenna, legs, and genitals (Spencer et al. 1982). In Drosophila, these adult structures all form from small discs of cells set aside early in development, the imaginal discs. The discs grow throughout larval development and then replace larval tissues during pupation and metamorphosis. The $d p p$ gene is expressed in a horizontal stripe in many different imaginal discs (Gelbart 1989; Masucci et al. 1990; Blackman et al. 1991). This stripe is located just anterior to the anterior/posterior disc domains that have been defined by cell lineage and expression of other genes. Interestingly, the stripe of expression does not correspond to the same axis that is disrupted by mutations in the $d p p$ gene (the proximodistal axis). The $d p p$ gene may function as part of a coordinant system that assigns positional identities to cells in the disc (Gelbart 1989; Bryant 1993).

\section{Worms and dauer larvae}

The soil nematode $C$. elegans enters a special dauer (enduring) larva stage when population density exceeds the food supply (Riddle 1988). Normal formation of dauer larva requires specific sensory neurons and is triggered by the balance between worm phermones and food signals. Genetic analysis has identified a series of daf mutations that are unable to form dauer larvae or that form larvae constitutively in the presence of abundant food (Riddle 1988; Vowels and Thomas 1992). Mutations in the daf-1 and daf-4 genes produce a dauer constitutive phenotype and appear to act at a similar point in the dauer pathway. daf- 4 encodes a type II transmembrane receptor kinase that binds mammalian BMPs but not activins or TGF- $\beta$ molecules (Estevez et al. 1993). daf-1 encodes a serine/threonine kinase receptor that probably belongs to the type I class (Georgi et al. 1990; see Table 2). These two receptors may heterodimerize with each other to form a functional receptor for a BMP-like molecule in C. elegans. The natural ligand is still unknown but could be encoded by one of the other loci grouped with daf-1 and daf-4 in the dauer pathway.

It is not yet clear where the receptor and ligand normally function. Transient expression of the wild type daf- 4 receptor in either Ll or dauer larva rescues the daf-4 mutant phenotype (Estevez et al. 1993), suggesting that the receptor is required for processing or execution of signals in the dauer larva sensory pathway, rather than for earlier generation or maintenance of responding cells. The studies on the daf-1 and daf- 4 genes establish the dauer larva pathway as an important new system for studying BMP/DVR signaling. Other daf genes may help in identifying molecules that act both upstream and downstream of BMP receptors. 


\section{Frogs and dominant negatives}

The large oocytes and embryos of amphibians have made them favorite objects of study by developmental biologists. In the last several years, a number of molecules from the TGF- $\beta$, fibroblast growth factor (FGF), and Wnt families have been found that affect the normal induction and patterning of mesoderm tissue during Xenopus development (Slack 1993). Several different members of the TGF- $\beta$ superfamily, including Vgl, activins, and BMPs, have striking effects on axis formation and mesoderm induction when added to embryos or prospective ectoderm tissue (Sive 1993; Thomsen and Melton 1993). Transcripts from the $V g 1$ gene also normally accumulate specifically in the vegetal half of developing oocytes (Fig. 3 ), strongly suggestive of a normal role in mesoderm induction (Weeks and Melton 1987). Recent experiments with chimeric proteins suggest that proteolytic processing of the $\mathrm{Vgl}$ precursor protein may further restrict its activity to particular regions of the developing embryo, possibly the Nieuwkoop signaling center in the dorsal vegetal region (Thomsen and Melton 1993).

No germ-line mutations are available in Xenopus to inactivate different growth factors and further test their postulated roles in normal development. The availability of cloned receptors, however, has made it possible to interfere with particular signaling pathways using a dominant negative approach (Amaya et al. 1991; Hemmati-Brivanlou and Melton 1992). By deleting the internal serine/threonine kinase domain of the activin type II receptor, it is possible to create a receptor that can still bind activin but should no longer be able to signal. When such constructs are injected into developing frog embryos, normal mesoderm formation is blocked (Hemmati-Brivanlou and Melton 1992). The inhibitory effects can be overcome by coinjecting wild-type activin II receptors. In contrast, another research group has reported partial axis duplications after injection of a different activin receptor construct containing a partial deletion of the cytoplasmic kinase domain (Nishimatsu et al. 1992a).

It is not clear whether truncated receptors act by sequestering activin itself or by dimerizing with and altering the function of normal receptors. The truncated receptors could also affect signaling by other members of the TGF- $\beta$ superfamily, a possibility made more likely by the discovery that some type I receptors can bind both TGF- $\beta$ and activins (Attisano et al. 1993; Ebner et al. 1993a). Nonetheless, the results to date already suggest that signaling by some member of the TGF- $\beta$ superfamily is necessary for normal mesoderm formation. The dominant negative receptor approach is likely to find broad use in testing the in vivo importance of signaling by other growth factors (including $\mathrm{Vgl}$ ) in frog development.

\section{Mouse and human mutations}

nodal Additional genetic evidence for an important role of a TGF- $\beta$ family member in early vertebrate de- velopment comes from a retroviral insertion in the mouse nodal gene. This insertion leads to a failure to form the primitive streak in early embryogenesis, a lack of axial mesoderm tissue, and an overproduction of ectoderm and extraembryonic ectoderm (Conlon et al. 1991; Iannaccone et al. 1992). The predicted nodal gene product is a TGF- $\beta$ superfamily member about equally related to activins and BMPs (Zhou et al. 1993). The secreted nature of the product is consistent with previous studies showing that the mutant phenotype is cell nonautonomous (Conlon et al. 1991). Whole-mount in situ experiments suggest that nodal is expressed specifically at the tip of the primitive streak in a region homologous to Henson's node in chicks. The mutant phenotype is first manifest prior to the appearance of the node, however, and PCR experiments suggest that the gene is also expressed at earlier stages in unknown regions (Zhou et al. 1993). The mutant phenotype and expression in the node both suggest that the nodal gene product plays an important role in mesoderm formation in mice. More detailed understanding of the mechanism of action of nodal will likely come from studies of its effects on mesoderm formation and patterning in Xenopus.

TGF- $\beta 1$ In the mouse, it is now possible to use homologous recombination in embryonic stem (ES) cells to construct mutations in virtually any cloned gene. Two members of the TGF- $\beta$ superfamily have already been knocked out by this approach, and mutations in many other family members should be reported in the next year or two.

Animals homozygous for null mutations in the $T G F$ $\beta 1$ gene survive until birth with no apparent morphological abnormalities (Shull et al. 1992; Kulkarni et al. 1993). The animals subsequently develop a massive immune infiltration in many different organs and usually die around weaning age. These results suggest that TGF- $\beta$ normally suppresses immune reactions, a conclusion that is strongly supported by the known effects of TGF- $\beta 1$ on many immune cells (Ruscetti and Palladino 1991).

Although newborn mutant animals lack a functional copy of the TGF- $\beta 1$ gene, recent immunohistochemical studies suggest that they nonetheless appear to contain significant levels of TGF- $\beta 1$ protein (J. Letterio, A. Geiser, and A. Roberts, unpubl.). Potential sources are the maternal circulation or the milk. The presence of maternal TGF- $\beta 1$ may mask many developmental consequences of the TGF- $\beta 1$ mutations. Similar potential complications should be kept in mind when interpreting the effects of mutations in other members of the TGF- $\beta$ superfamily.

Inho ES cells have also been used to construct mutations in the Inh $\alpha$ gene (Matzuk et al. 1992). Inhibins were originally identified because of their ability to suppress production of follicle-stimulating hormone (FSH) from pituitary cells. They are normally expressed in the gonads and may provide an important negative feedback signal that helps in regulating circulating FSH levels. 
Two different forms of inhibin exist, each a heterodimer of a common $\alpha$-subunit and one of two different $\beta$-subunits ( $\beta$ A or B). Inactivation of the $\alpha$-subunit should disrupt the formation of both forms of inhibin, without disrupting the ability of the $\beta \mathrm{A}$ and $\beta$ B subunits to associate with one another to make activins. Animals homozygous for the Inh $\alpha$ mutations are viable and have normal secondary sexual characteristics (Matzuk et al. 1992). Both males and females are infertile, however, and all of the animals develop tumors of gonadal stromal cells. Levels of FSH are elevated two- to threefold at 1-3 months of age, and elevated levels earlier in development could contribute to tumor formation. Alternatively, inhibin could normally act as a secreted signal that locally inhibits the proliferation of gonadal stromal cells.

To date, all of the Inh $\alpha$ mutants have been born from mothers that are themselves heterozygous for the Inh $\alpha$ mutation. Levels of inhibin protein have not yet been reported in the mutant mice, and it is possible that maternal inhibin masks other developmental consequences of Inh $\alpha$ mutations.

MIS MIS was originally isolated based on its ability to cause regression of the embryonic duct system that develops into oviducts and uterus (Lee and Donahoe 1993). This duct system is present in early mammalian embryos of both sexes but regresses in males. The only known site of expression of the MIS gene during mouse embryonic development is in the Sertoli cells of the male testes (Munsterberg and Lovell 1991). If the gene is misexpressed in female transgenic mice using a metallothionine promoter, it inhibits normal Müllerian duct differentiation and blocks formation of the uterus and oviducts (Behringer et al. 1990). Conversely, human mutations that inactivate the gene lead to persistence of Müllerian duct structures in males (Knebelmann et al. 1991). There is thus an excellent collection of studies showing that this gene is necessary, sufficient, and expressed at the right time and place to control Müllerian duct regression during normal development.

BMP5 A large fraction of the TGF- $\beta$ superfamily now consists of proteins isolated on the basis of their ability to induce formation of new bone and cartilage when injected under the skin or into muscles of rodents, or isolated because of strong homology to such factors (Rosen and Thies 1992). Although there have been many doubts about the physiological relevance of the heterotopic bone formation assay, the first mutations identified in a mammalian BMP gene strongly support a key role for BMPs in normal skeletal development.

Mutations at the mouse short ear locus alter the size, shape, and number of many different skeletal elements, greatly reduce the size of the external ear, and decrease the repair of bone fractures in adults (Green 1968). This gene was recently isolated by chromosome walking and shown to encode BMP5, one of eight known mammalian BMPs. Viable mutations at the short ear locus consist of deletions, translocations, or point mutations that either completely eliminate BMP5-coding sequences or alter key amino acid residues (Kingsley et al. 1992 and manuscript in preparation).

Short-eared mice have defects in the earliest stage of normal skeletal formation, the condensation of mesenchyme cells into the rough outlines of future skeletal elements. At specific anatomical locations, condensations are either missing or have altered shapes and sizes (Green and Green 1942). Expression studies have shown that transcripts from the BMP5 gene are expressed in complex patterns that are coextensive with regions of condensing fibroblasts (J. King, P. Marker, and D. Kingsley, in prep.). Together with data showing that purified BMP5 protein can induce local formation of new bone and cartilage when implanted at new sites in adult animals (Wozney 1992), the genetic and expression data strongly suggest that $B M P 5$ gene plays a key role in initiating the formation of particular skeletal features in higher animals. Various defects in adult animals, including the reduced rate of repair of bone fractures in short ear mice, suggest that BMP5 may also be required for growth and repair of skeletal structures after birth (Green 1958).

Why are the alterations in short ear mice confined to particular skeletal features? Many other BMP molecules are able to induce ectopic bone and cartilage, suggesting that the vertebrate genome has a large collection of molecules that could provide osteoinductive stimuli during normal development (Wang et al. 1990; Hammonds et al. 1991; Sampath et al. 1992; Wozney 1992). The different genes may be responsible for skeletal formation in different body regions, with the overall form and pattern of the skeleton built up from the composite activity of the BMP signaling pathway in different regions (Kingsley 1994). This model predicts that mutations in other BMP genes will also disnupt specific morphological features in the skeleton, and that combining mutations in different genes will produce progressively more severe changes in the skeleton.

BMPs are also likely to play many other roles in normal development. Some of the genes are expressed in interesting patterns in nonskeletal tissues, frequently at sites of interaction between epithelial layers and mesenchyme (Lyons et al. 1989b; Lyons et al. 1990; Jones et al. 1991; Vainio et al. 1993). Xenopus homologs of BMP2, $B M P 4$, and BMP7 are expressed maternally (Dale et al. 1992; Nishimatsu et al. 1992b), and injections of BMP4 into developing Xenopus embryos promotes formation of ventral/posterior mesoderm (Dale et al. 1992; Jones et al. 1992a). Misexpression of BMP4 in mice blocks proliferation of hair cells (Blessing et al. 1993). Beads soaked with BMP4 mimic the ability of dental epithelium to induce expression of several transcription factors and BMP4 itself in dental mesenchyme (Vainio et al. 1993). Finally, short ear animals have an increased frequency of a number of soft tissue abnormalities, including lung cysts, liver granulomas, and hydrotic kidneys /Green 1968). Some of these defects may reflect a normal requirement for BMP5 expression in soft tissue development. 


\section{Conclusions and perspectives}

The studies to date illustrate several key points about the TGF- $\beta$ superfamily. It is striking that related genes show up in similar processes in vastly different organisms. TGF- $\beta$ family members or BMP-1/tolloid-like proteins are clearly implicated in dorsoventral patterning of Drosophila embryos, sea urchin blastula, Xenopus and mouse mesoderm, and chicken neural tube (Figure 3). In both Drosophila and Xenopus TGF- $\beta$ family members induce different tissue types at different concentrations. Gradients of the activity of these molecules, together with different concentration thresholds for cellular responses, may be a fundamental mechanism for assigning cell identities along an embryonic axis. Members of the family are also expressed at many sites of mesenchymalepithelial interactions in organisms from flies to mice. These common roles may reflect ancient evolutionary functions in axis formation and tissue interaction that already existed in the common ancestors of arthropods and chordates.

It is also clear that individual members of the family can play multiple roles in a given organism. This has been demonstrated most clearly for $d p p$, which functions in dorsoventral axis formation, gut formation, and patterning of imaginal discs. Interesting, the cis-acting regulatory sequences that control these different functions map to different regions of the gene and are largely separable from one another (Masucci et al. 1990; Blackman et al. 1991; Huang et al. 1993; Hursh et al. 1993; Masucci and Hoffmann 1993). The mosaic structure of the regulatory regions gives the strong impression of a gene that has been coopted for different functions in Drosophila by piecemeal addition of new control elements.

As might be expected, the same ancestral genes have been utilized for some unique functions in different organisms. Drosophila BMP-like proteins clearly do not make bone and cartilage in flies but will when injected into mammals (Sampath et al. 1993). Homologous genes in mammals appear to be required for normal formation of skeletal elements, a role that they must have assumed after the divergence of vertebrates and invertebrates.

The mechanisms by which similar TGF- $\beta$ family members are coupled to different responses in different tissues and organisms are still unknown. Multiple receptor isoforms, multiple subunits, and combinatorial interactions between receptor subunits undoubtedly account for some of the diversity of responses to members of the family. The substrates for the receptors are still unknown, and an enormous amount of work remains to be done to determine the pathway of receptor signaling in any one tissue, and how this pathway differs in different cells.

Perhaps the biggest surprise in the last decade of work in biology has been that very different looking organisms are built using similar molecules and developmental pathways. This may seem obvious after 10 years of revelations showing that homeo domain proteins, steroid receptors, tyrosine kinase receptors, ras signaling, and
TGF- $\beta$ family members are present in many different animals and often play similar roles in cell-cell communication or axis formation. For many years, however, most people thought that only basic cellular metabolism would be ancient and universal. It now seems clear that many basic mechanisms of axis formation and tissue interaction also existed in the common ancestors of modern metazoans. Future studies of the TGF- $\beta$ superfamily should profit enormously from the realization that the same signaling pathways appear to underlie key steps in sea urchin, fly, worm, frog, chick, mouse, and human development. The interacting molecules and pathways found in any of these organisms will likely be immediately relevant to studies of a wide variety of biological phenomenon associated with TGF- $\beta$ superfamily members in other systems.

\section{Acknowledgments}

I thank Anita Roberts, Don Riddle, Joan Massague, and Arend Sidow for useful discussions and communicating data before publication. Work in my laboratory has been supported by Alfred and Katherine Heller and the Clarence E. Heller Charitable Foundation, by a Research Scholar Grant from the Lucille P. Markey Charitable Trust, and by the National Institutes of Health.

\section{References}

Amaya, E., T.J. Musci, and M.W. Kirschner. 1991. Expression of a dominant negative mutant of the FGF receptor disrupts mesoderm formation in Xenopus embryos. Cell 66: 257270.

Attisano, L., J.L. Wrana, S. Cheifetz, and J. Massague. 1992. Novel activin receptors: Distinct genes and alternative mRNA splicing generate a repertoire of serine/threonine kinase receptors. Cell 68: 97-108.

Attisano, L., J. Carcamo, F. Ventura, F.M.B. Weis, J. Massagué, and J.L. Wrana. 1993. Identification of human activin and TGF-beta type I receptors that form heteromeric kinase complexes with type II receptors. Cell 75: 671-680.

Basler, K., T. Edlund, T.M. Jessell, and T. Yamada. 1993. Control of cell pattern in the neural tube: Regulation of cell differentiation by dorsalin-1, a novel TGF beta family member. Cell 73: 687-702.

Behringer, R.R., R.L. Cate, G.J. Froelick, R.D. Palmiter, and R.L. Brinster. 1990. Abnormal sexual development in transgenic mice chronically expressing mullerian inhibiting substance. Nature 345: 167-170.

Blackman, R.K., M. Sanicola, L.A. Raftery, T. Gillevet, and W.M. Gelbart. 1991. An extensive 3' cis-regulatory region directs the imaginal disk expression of decapentaplegic, a member of the TGF-beta family in Drosophila. Development 111: 657-666.

Blessing, M., L.B. Nanney, L.E. King, C.M. Jones, and B.L. Hogan. 1993. Transgenic mice as a model to study the role of TGF- $\beta$-related molecules in hair follicles. Genes \& Dev. 7: 204-215.

Boyer, J., S. Pascolo, G.F. Richard, and B. Dujon. 1993. Sequence of a $7.8 \mathrm{~kb}$ segment on the left arm of yeast chromosome XI reveals four open reading frames, including the CAP1 gene, an intron-containing gene and a gene encoding a homolog to the mammalian UOG-1 gene. Yeast 9: 279-287. 
Bryant, P.J. 1993. The polar coordinate model goes molecular. Science 259: 471-472.

Burt, D.W., and I.R. Paton. 1992. Evolutionary origins of the transforming growth factor-beta gene family. DNA Cell Biol. 11: 497-510.

Celeste, A.J., J.A. Iannazzi, R.C. Taylor, R.M. Hewick, V. Rosen, E.A. Wang, and J.M. Wozney. 1990. Identification of transforming growth factor beta family members present in boneinductive protein purified from bovine bone. Proc. Natl. Acad. Sci. 87: 9843-9847.

Conlon, F.L., K.S. Barth, and E.J. Robertson. 1991. A novel retrovirally induced embryonic lethal mutation in the mouse: Assessment of the developmental fate of embryonic stem cells homozygous for the 413.d proviral integration. Development 111: 969-981.

Dale, L., G. Howes, B.M. Price, and J.C. Smith. 1992. Bone morphogenetic protein 4: A ventralizing factor in early Xenopus development. Development 115: 573-585.

Daopin, S., K.A. Piez, Y. Ogawa, and D.R. Davies. 1992. Crystal structure of transforming growth factor-beta 2: An unusual fold for the superfamily. Science 257: 369-373.

Doctor, J.S., P.D. Jackson, K.E. Rashka, M. Visalli, and F.M. Hoffmann. 1992. Sequence, biochemical characterization, and developmental expression of a new member of the TGFbeta superfamily in Drosophila melanogaster. Dev. Biol. 151: 491-505.

Ebner, R., R.-H. Chen, S. Lawler, T. Zioncheck, and R. Derynck. 1993a. Determination of type I receptor specificity by the type II receptors for TGF-beta or activin. Science 262: 900902.

Ebner, R., R.H. Chen, L. Shum, S. Lawler, T.F. Zioncheck, A. Lee, A.R. Lopez, and R. Derynck. 1993b. Cloning of a type I TGF-beta receptor and its effect on TGF-beta binding to the type II receptor. Science 260: 1344-1348.

Estevez, M., L. Attisano, J.L. Wrana, P.S. Albert, J. Massagué, and D.L. Riddle. 1993. The daf-4 gene encodes a bone morphogenetic protein receptor controlling c. elegans daver larva development. Nature 365: 644-649.

Felsenstein, I. 1985. Confidence limits on phylogenies: An approach using the bootstrap. Evolution 39: 783-791.

Ferguson, E.L. and K.V. Anderson. 1992a. Decapentaplegic acts as a morphogen to organize dorsal-ventral pattern in the Drosophila embryo. Cell 71: 451-461.

1992b. Localized enhancement and repression of the activity of the TGF-B family member, decapentaplegic, is necessary for dorsal-ventral pattern formation in the Drosophila embryo. Development 114: 583-597.

Franzén, P., P. ten Dijke, H. Ichijo, H. Yamashita, P. Schulz, C.H. Heldin, and K. Miyazono. 1993. Cloning of a TGF-B type 1 receptor that forms a heteromeric complex with the TGF- $\beta$ type II receptor. Cell 75: 681-692.

Gelbart, W.M. 1989. The decapentaplegic gene: A TGF-beta homologue controlling pattern formation in Drosophila. Development (Suppl.) 107: 65-74.

Gentry, L.E. and B.W. Nash. 1990. The pro domain of pre-protransforming growth factor beta 1 when independently expressed is a functional binding protein for the mature growth factor. Biochemistry 29: 6851-6857.

Georgi, L.L., P.S. Albert, and D.L. Riddle. 1990. daf-1, a C. elegans gene controlling dauer larva development, encodes a novel receptor protein kinase. Cell 61: 635-645.

Gray, A.M. and A.J. Mason. 1990. Requirement for activin A and transforming growth factor-beta 1 pro-regions in homodimer assembly. Science 247: 1328-1330.

Green, E.L. and M.C. Green. 1942. The development of three manifestations of the short ear gene in the mouse. J. Mor- phol. 70: 1-19.

Green, J.B., H.V. New, and J.C. Smith. 1992. Responses of embryonic Xenopus cells to activin and FGF are separated by multiple dose thresholds and correspond to distinct axes of the mesoderm. Cell 71: 731-739.

Green, M.C. 1958. Effects of the short ear gene in the mouse on cartilage formation in healing bone fractures. I. Exp. Zool. 137: 75-88.

-1968. Mechanism of the pleiotropic effects of the short ear mutant gene in the mouse. J. Exp. Zool. 167: 129-150.

Hammonds, R.J., R. Schwall, A. Dudley, L. Berkemeier, C. Lai, J. Lee, N. Cunningham, A.H. Reddi, W.I. Wood, and A.J. Mason. 1991. Bone-inducing activity of mature BMP-2b produced from a hybrid BMP-2a/2b precursor. Mol. Endocrinol. 5: $149-155$.

He, W.W., M.L. Gustafson, S. Hirobe, and P.K. Donahoe. 1993. Developmental expression of four novel serine/threonine kinase receptors homologous to the activin/transforming growth factor-beta type II receptor family. Dev. Dynamics 196: 133-142.

Hemmati-Brivanlou, A. and D.A. Melton. 1992. A truncated activin receptor inhibits mesoderm induction and formation of axial structures in Xenopus embryos. Nature 359: 609614.

Higgins, D.G., A.J. Bleasby, and R. Fuchs. 1992. CLUSTAL V: Improved software for multiple sequence alignment. Comput. Appl. Biosci. 8: 189-191.

Huang, J.D., D.H. Schwyter, J.M. Shirokawa, and A.J. Courey. 1993. The interplay between multiple enhancer and silencer elements defines the pattern of decapentaplegic expression. Genes \& Dev. 7: 694-704.

Hursh, D.A., R.W. Padgett, and W.M. Gelbart. 1993. Cross regulation of decapentaplegic and Ultrabithorax transcription in the embryonic visceral mesoderm of Drosophila. Devel opment 117: 1211-1222.

Iannaccone, P.M., X. Zhou, M. Khokha, D. Boucher, and M.R. Kuehn. 1992. Insertional mutation of a gene involved in growth regulation of the early mouse embryo. Dev. Dynamics 194: 198-208.

Immerglück, K., P.A. Lawrence, and M. Bienz. 1990. Induction across germ layers in Drosophila mediated by a genetic cascade. Cell 62: 261-268.

Inagaki, M., A. Moustakas, H.Y. Lin, H.F. Lodish, and B.I. Carr. 1993. Growth inhibition by transforming growth factor beta (TGF-beta) type I is restored in TGF-beta-resistant hepatoma cells after expression of TGF-beta receptor type II cDNA. Proc. Natl. Acad. Sci. 90: 5359-5363.

Jones, C.M., K.M. Lyons, and B.L. Hogan. 1991. Involvement of bone morphogenetic protein-4 (BMP-4) and Vgr-1 in morphogenesis and neurogenesis in the mouse. Development 111: $531-542$.

Jones, C.M., K.M. Lyons, P.M. Lapan, C.V. Wright, and B.L. Hogan. 1992a. DVR-4 (bone morphogenetic protein-4) as a posterior-ventralizing factor in Xenopus mesoderm induction. Development 115: 639-647.

Jones, C.M., C.D. Simon, J.L. Guenet, and B.L. Hogan. 1992b. Isolation of $\mathrm{Vgr}-2$, a novel member of the transforming growth factor-beta-related gene family. Mol. Endocrinol. 6: 1961-1968.

Kanzaki, T., A. Olofsson, A. Moren, C. Wernstedt, U. Hellman, K. Miyazono, W.L. Claesson, and C.H. Heldin. 1990. TGFbeta 1 binding protein: A component of the large latent complex of TGF-beta 1 with multiple repeat sequences. Cell 61: 1051-1061.

Kingsley, D.M. 1994. What do BMPs do in mammals? Clues from the mouse short ear mutation. Trends Genet. 10: 16- 
21.

Kingsley, D.M., A.E. Bland, J.M. Grubber, P.C. Marker, L.B. Russell, N.G. Copeland, and N.A. Jenkins. 1992. The mouse short ear skeletal morphogenesis locus is associated with defects in a bone morphogenetic member of the TGF- $\beta$ superfamily. Cell 71: 399-410.

Knebelmann, B., L. Boussin, D. Guerrier, L. Legeai, A. Kahn, N. Josso, and J.Y. Picard. 1991. Anti-Mullerian hormone Bruxelles: A nonsense mutation associated with the persistent Mullerian duct syndrome. Proc. Natl. Acad. Sci. 88: 37673771.

Kulkarni, A.B., C.G. Huh, D. Becker, A. Geiser, M. Lyght, K.C. Flanders, A.B. Roberts, M.B. Sporn, J.M. Ward, and S. Karlsson. 1993. Transforming growth factor beta 1 null mutation in mice causes excessive inflammatory response and early death. Proc. Natl. Acad. Sci. 90: 770-774.

Laiho, M., M.B. Weis, and J. Massague. 1990. Concomitant loss of transforming growth factor (TGF)-beta receptor types I and II in TGF-beta-resistant cell mutants implicates both receptor types in signal transduction. J. Biol. Chem. 265: 18518-18524.

Lee, M.M. and P.K. Donahoe. 1993. Mullerian inhibiting substance: A gonadal hormone with multiple functions. Endocrinol. Rev. 14: 152-164.

Lee, S.J. 1991. Expression of growth/differentiation factor 1 in the nervous system: Conservation of a bicistronic structure. Proc. Natl. Acad. Sci. 88: 4250-4254.

Lepage, T., C. Ghiglione, and C. Gache. 1992. Spatial and temporal expression pattern during sea urchin embryogenesis of a gene coding for a protease homologous to the human protein BMP-1 and to the product of the Drosophila dorsal-ventral patterning gene tolloid. Development 114: 147-163.

Lin, H.Y. and H.F. Lodish. 1993. Receptors for the TGF-beta superfamily: Multiple polypeptides and serine/threonine kinases. Trends Cell. Biol. 3: 14-19.

Lin, H.Y., X.F. Wang, E.E. Ng, R.A. Weinberg, and H.F. Lodish. 1992. Expression cloning of the TGF-beta type II receptor, a functional transmembrane serine/threonine kinase. Cell 68: $775-785$.

Lin, L.F., D.H. Doherty, J.D. Lile, S. Bektesh, and F. Collins. 1993. GDNF: A glial cell line-derived neurotrophic factor for midbrain dopaminergic neurons. Science 260: 1130-1132.

Lopez, C.F., J.L. Wrana, and J. Massague. 1993. Betaglycan presents ligand to the TGF beta signaling receptor. Cell 73: 1435-1444.

Luyten, F.P., N.S. Cunningham, S. Ma, N. Muthukumaran, R.G. Hammonds, W.B. Nevins, W.I. Woods, and A.H. Reddi. 1989. Purification and partial amino acid sequence of osteogenin, a protein initiating bone differentiation. J. Biol. Chem. 264: 13377-13380.

Lyons, K., J.L. Graycar, A. Lee, S. Hashmi, P.B. Lindquist, E.Y. Chen, B.L. Hogan, and R. Derynck. 1989a. Vgr-1, a mammalian gene related to Xenopus Vg-1, is a member of the transforming growth factor beta gene superfamily. Proc. Natl. Acad. Sci. 86: 4554-4558.

Lyons, K.M., R.W. Pelton, and B.L. Hogan. 1989b. Patterns of expression of murine Vgr-1 and BMP-2a RNA suggest that transforming growth factor- $\beta$-like genes coordinately regulate aspects of embryonic development. Genes \& Dev. 3: $1657-1668$.

Lyons, K.M., R.W. Pelton, and B.L. Hogan. 1990. Organogenesis and pattern formation in the mouse: RNA distribution patterns suggest a role for bone morphogenetic protein-2A (BMP-2A). Development 109: 833-844.

Lyons, K.M., C.M. Jones, and B.L.M. Hogan. 1991. The DVR gene family in embryonic development. Trends Genet.
7: 408-412.

Massague, J. 1990. The transforming growth factor-beta family. Annu. Rev. Cell Biol. 6: 597-641.

_ 1992. Receptors for the TGF-beta family. Cell 69: 10671070.

Masucci, J.D. and F.M. Hoffmann. 1993. Identification of two regions from the Drosophila decapentaplegic gene required for embryonic midgut development and larval viability. Dev. Biol. 159: 276-287.

Masucci, J.D., R.J. Miltenberger, and F.M. Hoffmann. 1990. Pattern-specific expression of the Drosophila decapentaplegic gene in imaginal disks is regulated by 3' cis-regulatory elements. Genes \& Dev. 4: 2011-2023.

Mathews, L.S. and W.W. Vale. 1991. Expression cloning of an activin receptor, a predicted transmembrane serine kinase. Cell 65: 973-982.

Mathews, L.S., W.W. Vale, and C.R. Kintner. 1992. Cloning of a second type of activin receptor and functional characterization in Xenopus embryos. Science 255: 1702-1705.

Matsuzaki, K., J. Xu, F. Wang, W.L. McKeehan, L. Krummen, and M. Kan. 1993. A widely expressed transmembrane serine/threonine kinase that does not bind activin, inhibin, transforming growth factor beta, or bone morphogenic factor. J. Biol. Chem. 268: 12719-12723.

Matzuk, M.M., M.J. Finegold, J.G. Su, A.J. Hsueh, and A. Bradley. 1992. Alpha-inhibin is a tumour-suppressor gene with gonadal specificity in mice. Nature 360: 313-319.

McDonald, N.Q. and W.A. Hendrickson. 1993. A structural superfamily of growth factors containing a cystine knot motif. Cell 73: 421-424.

McPherron, A.C. and S.J. Lee. 1993. GDF-3 and GDF-9: Two new members of the transforming growth factor-beta superfamily containing a novel pattern of cysteines. J. Biol. Chem. 268: 3444-3449.

Miyazono, K., A. Olofsson, P. Colosetti, and C.H. Heldin. 1991. A role of the latent TGF-beta 1-binding protein in the assembly and secretion of TGF-beta 1. EMBO $/$. 10: 10911101.

Moses, H.L., E.Y. Yang, and J.A. Pietenpol. 1990. TGF-beta stimulation and inhibition of cell proliferation: New mechanistic insights. Cell 63: 245-247.

Munsterberg, A. and B.R. Lovell. 1991. Expression of the mouse anti-mullerian hormone gene suggests a role in both male and female sexual differentiation. Development 113: 613624.

Nishimatsu, S., M. Iwao, T. Nagai, S. Oda, A. Suzuki, M. Asashima, K. Murakami, and N. Ueno. 1992a. A carboxyl-terminal truncated version of the activin receptor mediates activin signals in early Xenopus embryos. FEBS Lett. 312: 169-173.

Nishimatsu, S., A. Suzuki, A. Shoda, K. Murakami, and N. Ueno. 1992b. Genes for bone morphogenetic proteins are differentially transcribed in early amphibian embryos. Biochem. Biophys. Res. Commun. 186: 1487-1495.

Ozkaynak, E., D.C. Rueger, E.A. Drier, C. Corbett, R.J. Ridge, T.K. Sampath, and H. Oppermann. 1990. OP-1 cDNA encodes an osteogenic protein in the TGF-beta family. EMBO J. 9: 2085-2093.

Ozkaynak, E., P.N. Schnegelsberg, D.F. Jin, G.M. Clifford, F.D. Warren, E.A. Drier, and H. Oppermann. 1992. Osteogenic protein-2. A new member of the transforming growth factorbeta superfamily expressed early in embryogenesis. J. Biol. Chem. 267: 25220-25227.

Padgett, R.W., J.M. Wozney, and W.M. Gelbart. 1993. Human BMP sequences can confer normal dorsal-ventral patterning in the Drosophila embryo. Proc. Natl. Acad. Sci. 90: 29052909. 
Panganiban, G.E., R. Reuter, M.P. Scott, and F.M. Hoffmann. 1990. A Drosophila growth factor homolog, decapentaplegic, regulates homeotic gene expression within and across germ layers during midgut morphogenesis. Development 110: 1041-1050.

Qian, S.W., J.K. Burmester, J.R. Merwin, J.A. Madri, M.B. Sporn, and A.B. Roberts. 1992. Identification of a structural domain that distinguishes the actions of the type 1 and 2 isoforms of transforming growth factor beta on endothelial cells. Proc. Natl. Acad. Sci. 89: 6290-6294.

Reuter, R., G.E. Panganiban, F.M. Hoffmann, and M.P. Scott. 1990. Homeotic genes regulate the spatial expression of putative growth factors in the visceral mesoderm of Drosophila embryos. Development 110: 1031-1040.

Reynolds, S.D., L.M. Angerer, J. Palis, A. Nasir, and R.C. Angerer. 1992. Early mRNAs, spatially restricted along the animal-vegetal axis of sea urchin embryos, include one encoding a protein related to tolloid and BMP-1. Development 114: 769-786.

Riddle, D.L. 1988. The dauer larva. In The nematode Caenorhabditis elegans (ed. W.B. Wood), pp. 393-412. Cold Spring Harbor Laboratory, Cold Spring Harbor, New York.

Rosen, V. and R.S. Thies. 1992. The BMP proteins in bone formation and repair. Trends Genet. 8: 97-102.

Ruscetti, F.W. and M.A. Palladino. 1991. Transforming growth factor-beta and the immune system. Prog. Growth Factor Res. 3: 159-175.

St. Johnston, R.D. and W.M. Gelbart. 1987. Decapentaplegic transcripts are localized along the dorsal-ventral axis of the Drosophila embryo. EMBO J. 6: 2785-2791.

Sampath, T.K., J.C. Maliakal, P.V. Hauschka, W.K. Jones, H. Sasak, R.F. Tucker, K.H. White, J.E. Coughlin, M.M. Tucker, and R.H. Pang. 1992. Recombinant human osteogenic protein-1 (hOP-1) induces new bone formation in vivo with a specific activity comparable with natural bovine osteogenic protein and stimulates osteoblast proliferation and differentiation in vitro. J. Biol. Chem. 267: 20352-20362.

Sampath, T.K., K.E. Rashka, J.S. Doctor, R.F. Tucker, and F.M. Hoffmann. 1993. Drosophila transforming growth factor beta superfamily proteins induce endochondral bone formation in mammals. Proc. Natl. Acad. Sci. 90: 6004-6008.

Schlunegger, M.P. and M.G. Grutter. 1992. An unusual feature revealed by the crystal structure at $2.2 \AA$ resolution of human transforming growth factor-beta 2 . Nature 358: 430434.

Shimell, M.J., E.L. Ferguson, S.R. Childs, and M.B. O'Connor. 1991. The Drosophila dorsal-ventral patterning gene tolloid is related to human bone morphogenetic protein 1. Cell 67: 469-481.

Shull, M.M., I. Ormsby, A.B. Kier, S. Pawlowski, R.J. Diebold, M. Yin, R. Allen, C. Sidman, G. Proetzel, D. Calvin, N. Annunziata, and T. Doetschman. 1992. Targeted disruption of the mouse transforming growth factor-beta 1 gene results in multifocal inflammatory disease. Nature 359: 693-699.

Sive, H.L. 1993. The frog prince-ss: A molecular formula for dorsoventral patterning in Xenopus. Genes \& Dev. 7: 1-12.

Slack, J.M. 1993. Embryonic induction. Mech. Dev. 41: 91-107.

Spencer, F.A., F.M. Hoffmann, and W.M. Gelbart. 1982. Decapentaplegic: A gene complex affecting morphogenesis in Drosophila melanogaster. Cell 28: $451-461$.

Sporn, M.B. and A.B. Roberts. 1992. Transforming growth factor-beta: Recent progress and new challenges. J. Cell. Biol. 119: 1017-1021.

ten Dijke, P., H. Ichijo, P. Franzen, P. Schulz, J. Saras, H. Toyoshima, C.H. Heldin, and K. Miyazono. 1993. Activin receptor-like kinases: A novel subclass of cell-surface recep- tors with predicted serine/threonine kinase activity. Oncogene 8: 2879-2887.

Thomsen, G.H. and D.A. Melton. 1993. Processed Vg1 protein is an axial mesoderm inducer in Xenopus. Cell 74: 433-441.

Tsuji, T., F. Okada, K. Yamaguchi, and T. Nakamura. 1990. Molecular cloning of the large subunit of transforming growth factor type beta masking protein and expression of the mRNA in various rat tissues. Proc. Natl. Acad. Sci. 87: 8835-8839.

Vainio, S., I. Karavanova, A. Jowett, and I. Thesleff. 1993. Identification of BMP-4 as a signal mediating secondary induction between epithelial and mesenchymal tissues during early tooth development. Cell 75: 45-58.

Vowels, J.J. and J.H. Thomas. 1992. Genetic analysis of chemosensory control of dauer formation in Caenorhabditis elegans. Genetics 130: 105-123.

Wang, E.A., V. Rosen, J.S. D'Alessandro, M. Bauduy, P. Cordes, T. Harada, D.I. Israel, R.M. Hewick, K.M. Kerns, P. LaPan, D.P. Luxenberg, D. McQuaid, I.K. Moutsatsos, J. Nove, and J.M. Wozney. 1990. Recombinant human bone morphogenetic protein induces bone formation. Proc. Natl. Acad. Sci. 87: 2220-2224.

Wang, X., H. Lin, E. Ng-Eaton, J. Downward, H. Lodish, and R. Weinberg. 1991. Expression cloning and characterization of the TGF-beta type III receptor. Cell 67: 797-805.

Waterston, R., C. Martin, M. Craxton, C. Huynh, A. Coulson, L. Hillier, R. Durbin, P. Green, R. Shownkeen, N. Halloran, T.Hawkins, R. Wilson, M.Berks, Z. Du, K. Thomas, J. Thierry-Mieg, and J. Sulston. 1992. A survey of expressed genes in Caenorhabditis elegans. Nature Genet. 1: 114-23.

Weeks, D.L. and D.A. Melton. 1987. A maternal mRNA localized to the vegetal hemisphere in Xenopus eggs codes for a growth factor related to TGF- $\beta$ eta. Cell 51: 861-867.

Wharton, K.A., G.H. Thomsen, and W.M. Gelbart. 1991. Drosophila $60 \mathrm{~A}$ gene, another transforming growth factor beta family member, is closely related to human bone morphogenetic proteins. Proc. Natl. Acad. Sci. 88: 9214-9218.

Wharton, K.A., R.P. Ray, and W.M. Gelbart. 1993. An activity gradient of decapentaplegic is necessary for the specification of dorsal pattern elements in the Drosophila embryo. Development 117: 807-822.

Wozney, J.M. 1992. The bone morphogenetic protein family and osteogenesis. Mol. Reprod. Dev. 32: 160-167.

Wozney, J.M., V. Rosen, A.J. Celeste, L.M. Mitsock, M.J. Whitters, R.W. Kriz, R.M. Hewick, and E.A. Wang. 1988. Novel regulators of bone formation: Molecular clones and activities. Science 242: 1528-1534.

Wrana, J.L., L. Attisano, J. Carcamo, A. Zentella, J. Doody, M. Laiho, X.F. Wang, and J. Massague. 1992. TGF beta signals through a heteromeric protein kinase receptor complex. Cell 71: 1003-1014.

Yamazaki, Y., T. Saito, and T. Nohno. 1993. A new receptor protein kinase from chick embryo related to type II receptor for TGF-beta. DNA Sequence 3: 297-302.

Ying, S.Y. 1989. Inhibins, activins and follistatins. I. Steroid Biochem. 33: 705-713.

Zhou, X., H. Sasaki, L. Lowe, B.L. Hogan, and M.R. Kuehn. 1993. Nodal is a novel TGF-beta-like gene expressed in the mouse node during gastrulation. Nature 361: 543-547. 


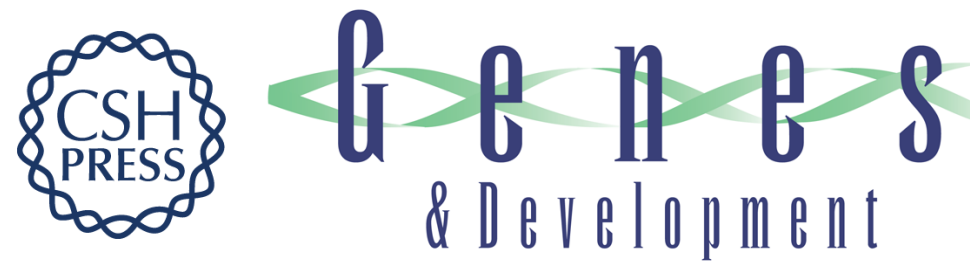

\section{The TGF-beta superfamily: new members, new receptors, and new genetic tests of function in different organisms.}

D M Kingsley

Genes Dev. 1994, 8:

Access the most recent version at doi:10.1101/gad.8.2.133

References This article cites 111 articles, 47 of which can be accessed free at:

http://genesdev.cshlp.org/content/8/2/133.full.html\#ref-list-1

License

Email Alerting

Service

Receive free email alerts when new articles cite this article - sign up in the box at the top right corner of the article or click here.

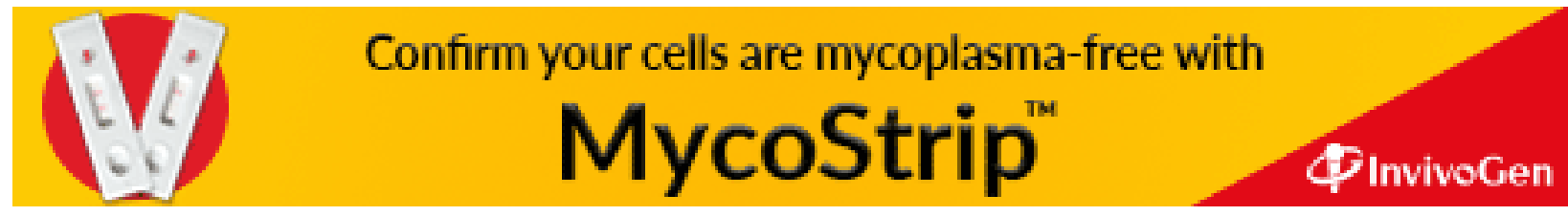

